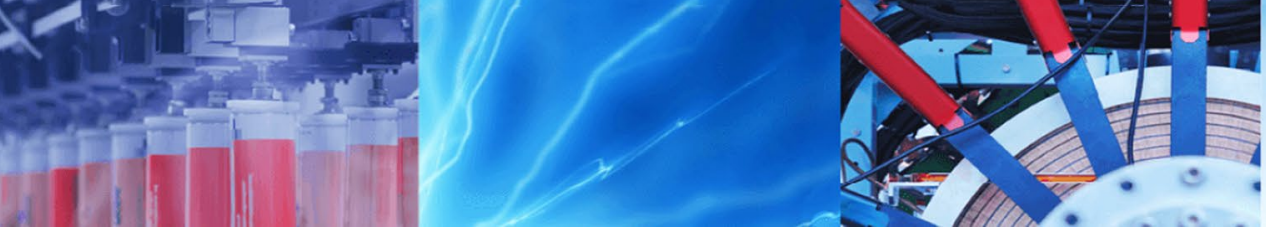

Research Article

\title{
Fe-Ni Invar alloy reinforced by WC nanoparticles with high strength and low thermal expansion
}

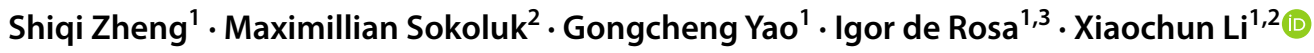

(c) Springer Nature Switzerland AG 2019

\begin{abstract}
Invar is a solid solution alloy that offers high-dimensional stability. It is challenging for traditional methods to strengthen Invar alloys without a significant increase in the coefficient of thermal expansion (CTE). In this work, WC nanoparticlereinforced Invar nanocomposite was manufactured. The microstructures, mechanical properties, and thermal expansion behavior were investigated. It was found that the Invar alloy was effectively strengthened by WC nanoparticle reinforcement without significant elevation of its CTE. The Invar-WC nanocomposite exhibits an enhanced yield and tensile strength of 440 and $795 \mathrm{MPa}$, an increase of $60 \%$ and $77 \%$ from commercial Invar alloy, and a moderate ductility of $22.7 \%$ in annealed state. In cold-rolled state, The Invar-WC nanocomposite exhibits a high tensile strength of $1050 \mathrm{MPa}$, an increase of $46 \%$ from commercial Invar alloy, while retaining $4.5 \%$ ductility. A record low CTE value of $2.61 \times 10^{-6} /{ }^{\circ} \mathrm{C}$ and an enhanced Young's modulus of $185 \mathrm{GPa}$, up from $140 \mathrm{GPa}$, were also achieved. It was found that WC leads to a lower CTE at higher temperature compared to unreinforced Invar.
\end{abstract}

Keywords Invar · Thermal expansion · High strength · Nanocomposite

\section{Introduction}

Invar is a binary solid solution alloy of Fe and $\mathrm{Ni}$ with a $\mathrm{Ni}$ content of around $36 \mathrm{wt} . \%$. Invar possesses a uniquely low coefficient of thermal expansion (CTE, $a_{25-100^{\circ} \mathrm{C}} \approx 1.5 \times 10^{-6} /{ }^{\circ} \mathrm{C}$ ) below its Curie temperature $\left(T_{c} \sim 277^{\circ} \mathrm{C}\right)[1]$. For this reason, Invar alloys are frequently used in a wide range of applications that require highdimensional stability, such as large telescopes, precision instruments, and core wires of long-distance power cable [2]. In recent years, Invar alloys with high mechanical strength have been subject to renewed interest for their application in aeronautic and aerospace industry, such as high-tolerance curing molds for composite materials and ultrahigh-stability structures for in-orbit and groundand-orbit multi-satellite operations $[3,4]$. Thus, the study of strengthening Invar alloy is of significance.
The strengthening of Invar alloy can be achieved primarily through three methods: grain refinement [5], plastic deformation (and severe plastic deformation, SPD) [6], and precipitation hardening [4, 7-9]. Vingradov et al. [8] reported that the tensile strength of Fe-36Ni Invar alloy can be increased to $912 \mathrm{MPa}$ by refining the grain size to $180 \mathrm{~nm}$ using equal channel angular pressing (ECAP). Morikawa et al. [5] demonstrated that Invar alloy rolled to $90 \%$ thickness reduction at cryogenic temperature (77 K) can reach $1250 \mathrm{MPa}$ in tensile strength due to the formation of deformation twins. The strengthening of Invar alloy through the precipitation of MC-type carbides, such as TiC, $\mathrm{VC}$, and $\mathrm{Mo}_{2} \mathrm{C}$, or intermetallics, such as $\gamma^{\prime}$-type $\mathrm{Ni}_{3} \mathrm{Ti}$ and $\mathrm{Ni}_{3} \mathrm{Al}$, was reported to be highly effective. Nakama et al. reported a Fe-Ni-V-C Invar alloy reaches a tensile strength of $1000 \mathrm{MPa}$ after a combination of solutionization, aging, which produces VC precipitates, and cold working [7, 9];

Xiaochun Li, xcli@seas.ucla.edu | ${ }^{1}$ Department of Materials Science and Engineering, University of California Los Angeles, Los Angeles 90095, USA. ²Department of Mechanical and Aerospace Engineering, University of California Los Angeles, Los Angeles 90095 , USA. ${ }^{3}$ Institute for Technology Advancement, University of California Los Angeles, Los Angeles 90095, USA. 
the same author reported the strengthening of Invar alloy containing $\mathrm{Ti}, \mathrm{V}$, and $\mathrm{C}$ through $\mathrm{TiC}$ and $\mathrm{VC}$ precipitation, and achieved $1100 \mathrm{MPa}$ tensile strength at peak aging condition [6]. Yahagi et al. reported a $\mathrm{Fe}-\mathrm{Ni}-\mathrm{Co}-\mathrm{Ti}$ Invar alloy strengthened by the precipitation of $\gamma^{\prime}$-type $\mathrm{Ni}_{3} \mathrm{Ti}$ intermetallics exhibits a tensile strength of $1313 \mathrm{MPa}$ after cold working [10]. Sridharan et al. reported a similar strengthening strategy using $\mathrm{Ni}_{3}(\mathrm{Al}, \mathrm{Ti})$ precipitates. After cold working, $1300 \mathrm{MPa}$ tensile strength was obtained [11].

It is notable that each of the aforementioned strengthening methods has its own drawback. As ultrafine-grained and nanograined Invar alloys are typically prepared by either deposition [12] or SPD [5], they typically exhibit relative low stability against grain growth [13] and have high equipment cost due to the use of processes like ECAP. While precipitation strengthening by MC-type carbides or intermetallics is proved to be highly effective, these methods typically result in an undesirable increase in the alloy's CTE value, up to $3-4 \times 10^{-6} /{ }^{\circ} \mathrm{C}[3,10]$. To this end, it is of interest to develop a simple method of strengthening Invar alloy effectively while preventing a significant increase in the CTE value.

Compared with conventional strengthening methods, the reinforcement of Invar alloy through nanosized lowthermal expansion ceramic particulates is not well studied. While using laser to process Invar alloy with ceramic microparticles, such as TiC [14], or joining Invar alloy with bulk ceramics, such as $\mathrm{Si}_{3} \mathrm{~N}_{4}$ [4], was reported, the manufacturing of bulk Invar alloy nanocomposites has not been studied so far.

In the present work, tungsten carbide (WC) nanoparticles were used to reinforce Invar alloy, due to the combination of high hardness, low CTE, and commercial availability of WC nanoparticles. The methodology involves easy-to-achieve powder metallurgy practice combined with regular hot and cold working, since currently a good method of incorporating WC nanoparticles into molten Invar in a regular liquid metallurgy scenario has not been developed. The mechanical strength of the WC/Invar was measured with and without cold working. The CTE values of WC/Invar and regular Invar, manufactured by the same process, were measured for comparison.

\section{Experimental}

WC nanoparticles (APS $150 \mathrm{~nm}$, US Research Nanomaterials) were used in this work. Its CTE is approximately $5.5 \times 10^{-6} /{ }^{\circ} \mathrm{C}[15]$. The Invar powder (325 mesh) used has a nominal composition of $\mathrm{Fe}-36.56 \mathrm{wt} . \% \mathrm{Ni}-0.34 \mathrm{wt} . \% \mathrm{Si}-$ 0.016 wt.\%C-0.03 wt.\%Mn (ESPI Metals). The Invar powder was first blended with 10 vol.\% WC nanoparticles, which are later referred to as "Invar-10WC." A small quantity of acetone was then introduced to the powder mixture to create the slurry. The slurry was treated with a Misonix sonicator for $10 \mathrm{~min}$ in order to break apart the WC clusters. The acetone was subsequently evaporated in an $80^{\circ} \mathrm{C}$ water bath. The powder was dried in a vacuum oven at $60^{\circ} \mathrm{C}$ for $2 \mathrm{~h}$. The dried powder was cold-compacted in a $2.5-\mathrm{cm}$-diameter steel cylindrical mold at $400 \mathrm{MPa}$ of pressure and was subjected to a pressureless sintering for $20 \mathrm{~min}$ at $1300^{\circ} \mathrm{C}$, under $1 \mathrm{~atm}$ argon protection, in an induction furnace. The sintered ingots were hot-forged at $1200^{\circ} \mathrm{C}$ into about 2 -mm-thick sheets and then cold-rolled by $25 \%$ thickness reduction to 1.5 -mm-thick sheets.

Tensile bars were cut using electrical discharge machining (EDM). The tensile bars had a $10 \mathrm{~mm} \times 4 \mathrm{~mm} \times 1.5 \mathrm{~mm}$ $(L \times W \times T)$ gage section. Prior to testing, a portion of the tensile bars was annealed at $1000^{\circ} \mathrm{C}$ for $1 \mathrm{~h}$ and the rest were left as-rolled. The tensile tests were conducted on an Instron universal testing system equipped with a $10 \mathrm{kN}$ load cell and a standard video extensometer. The tensile strain rate was $1 \times 10^{-3} / \mathrm{s}$.

Samples were prepared for scanning electron microscope (SEM) (Zeiss Supra 40VP) analysis using standard metallographic practice. CTE measurement was taken using ASTM E228 method in helium atmosphere from room temperature to $370{ }^{\circ} \mathrm{C}$ [16]. Prior to the measurement, the CTE samples were annealed at $1000{ }^{\circ} \mathrm{C}$ for $1 \mathrm{~h}$. For comparison purpose, the CTE of unreinforced Invar alloy, prepared using the same method, was also measured.

\section{Results}

\subsection{Microstructure of Invar-10WC}

The representative SEM micrograph of as-sintered Invar10WC sample is shown in Fig. 1a. In the Invar matrix, WC nanoparticles are well distributed, but appear as pseudoclusters, where the nanoparticles are dispersed (separated from each other). The as-sintered sample also has numerous large pores and a region of poor sintering quality, as shown in Fig. 1a bottom left. Due to the relatively short sintering time of $20 \mathrm{~min}$, no obvious growth is observed on the WC nanoparticles (Fig. 1a inset). The representative SEM micrograph of an as-forged Invar-10WC sample is shown in Fig. 1b. Compared to the as-sintered sample, the forging process is not able to alter the WC nanoparticle distribution in the Invar matrix. However, the forging process is effective in removing residual pores and breaking large WC nanoparticle pseudo-clusters into smaller ones. The relative density of the as-forged samples is around $99.3 \%$, as determined by the Archimedes method, 

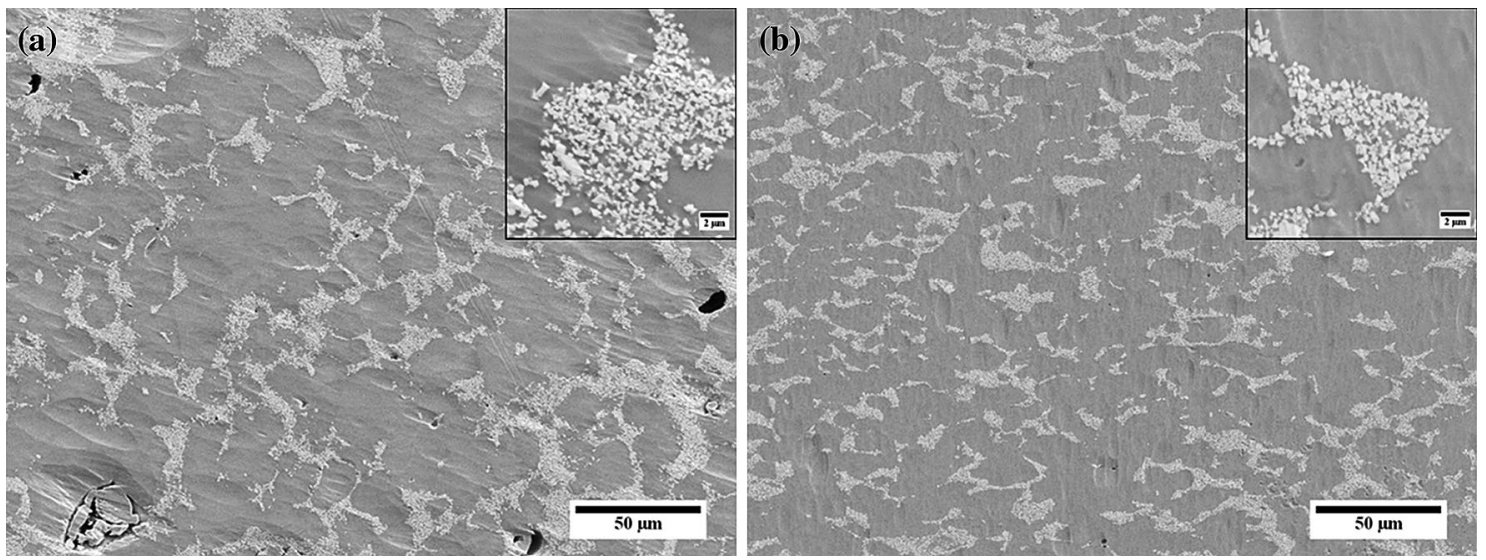

Fig. 1 SEM micrograph of Invar-10WC sample sintered at $1300^{\circ} \mathrm{C}$. $\mathbf{a}$ As-sintered; $\mathbf{b}$ as-forged. The scale bar on the insets is $2 \mu \mathrm{m}$

indicating the significant densification effect brought by the forging process.

\subsection{Mechanical properties and CTE of Invar-10WC samples}

Figure 2a shows the typical stress-strain curves of annealed and cold-rolled Invar-10WC samples. The annealed sample has a tensile strength of $800 \mathrm{MPa}$ and an elongation of $22.7 \%$. After cold rolling of $25 \%$ thickness reduction, a tensile strength of $1050 \mathrm{MPa}$ is obtained, $31 \%$ higher than that of the annealed sample. The cold-rolled sample has an elongation of $4.5 \%$.

Figure $2 \mathrm{~b}$ shows the CTE versus temperature curves of the Invar-10WC sample and the pure Invar sample as a control, herein named "Invar-OWC." The CTE at any given temperature is calculated by dividing the change in length of the sample by the change in the temperature, given by Eq. 1,

$\alpha_{\text {mean }}=\frac{\frac{L_{T}-L_{0}}{L_{0}}}{T-T_{0}}$

where $T_{0}$ is the starting temperature, $20^{\circ} \mathrm{C}, L_{0}$ is the initial sample length, and $L_{T}$ is the length of the sample at given temperature $T$. The CTE value is $2.61 \times 10^{-6} /{ }^{\circ} \mathrm{C}$ for the Invar10WC sample and $1.65 \times 10^{-6} /{ }^{\circ} \mathrm{C}$ for the Invar-0WC sample, in the temperature range of 20 to $100^{\circ} \mathrm{C}$.

The property combination of UTS and CTE of the Invar10WC sample is plotted in an Ashby chart in comparison with other engineering alloys and high-strength Invar from the literature (Fig. 3). While the mechanical strength of the Invar-10WC is slightly lower than that of $\mathrm{Fe}-\mathrm{Ni}-\mathrm{Co}-\mathrm{Ti}$ - and $\mathrm{Fe}-\mathrm{Ni}$-Co-Al-type high-strength Invar alloys, the CTE of
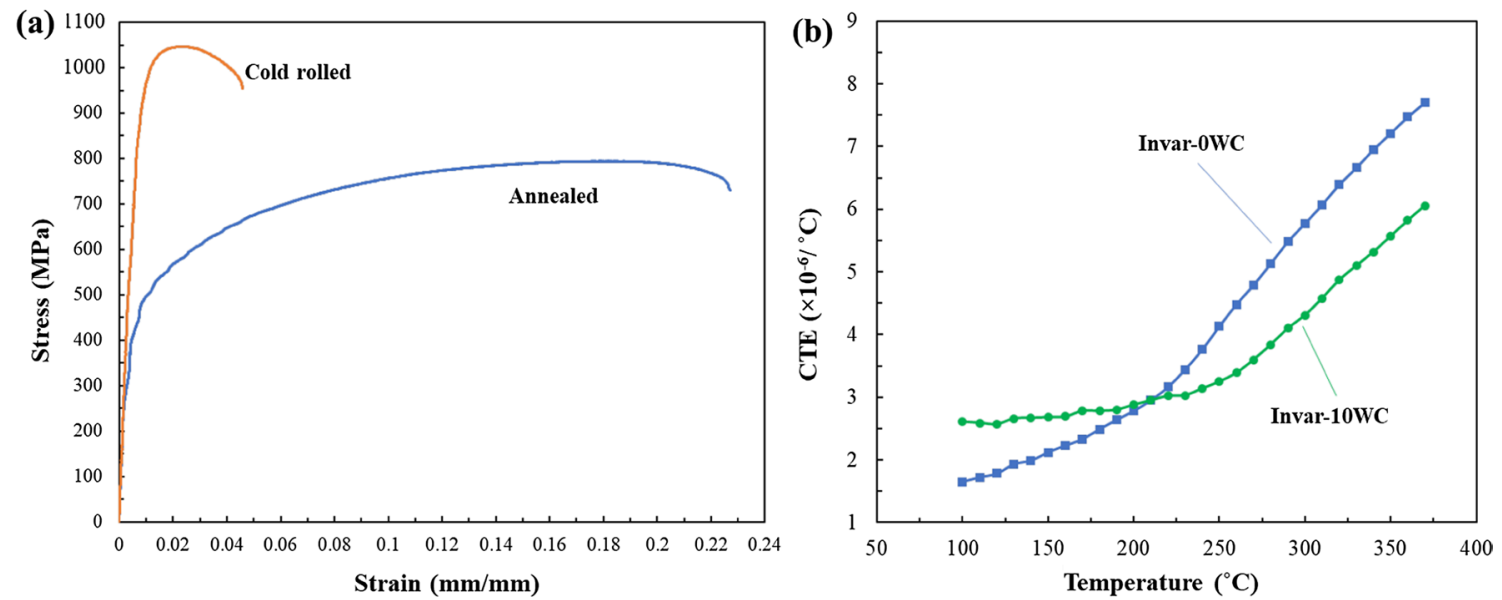

Fig. 2 a Typical stress-strain curves of annealed and cold-rolled ( $25 \%$ thickness reduction) Invar-10WC samples. b CTE versus temperature curves of Invar-10WC (green filled circle) sample and control sample (blue filled square) 


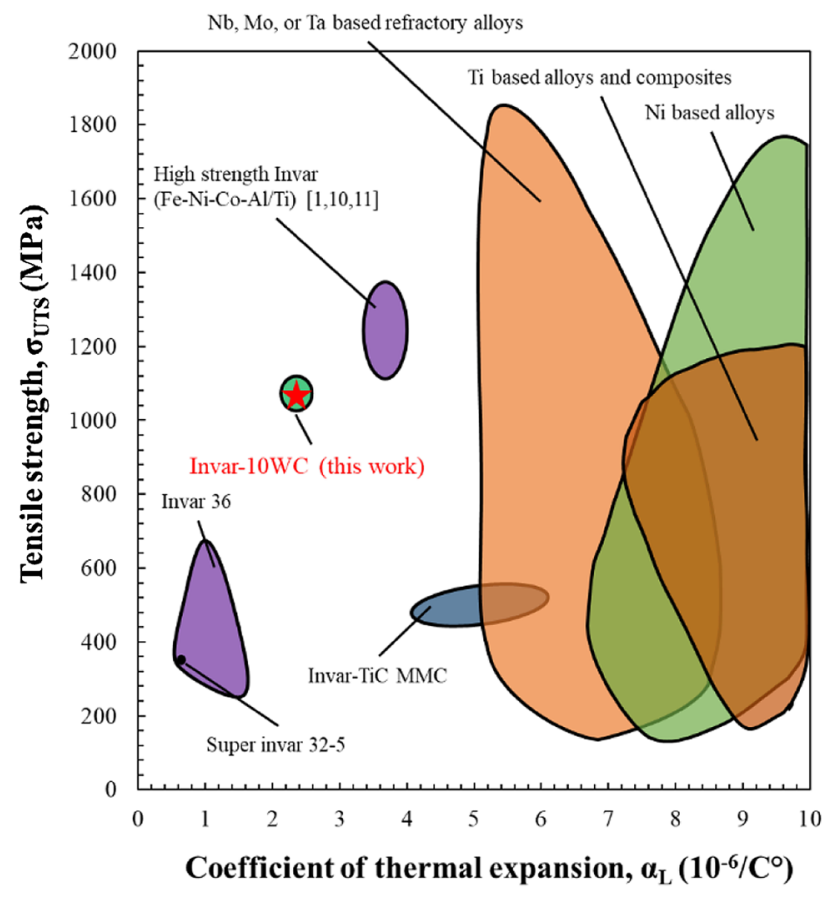

Fig. 3 Ashby plot displaying the property combination of UTS versus CTE

the Invar-10WC is significantly lower. The outstandingly low CTE allows the Invar-10WC nanocomposite to occupy a unique property space on the Ashby chart.

\section{Discussion}

\subsection{Microstructure of Invar-10WC}

Based on the SEM micrographs (Fig. 1), the forged Invar10WC sample consists of a dual-phase-like microstructure, in which densely packed, WC-rich clusters are randomly distributed throughout the WC nanoparticle-free austenite matrix. The insets in Fig. 1 indicate that the WC-rich clusters are well infiltrated by the matrix. This microstructure is likely the result of lack of ball milling during the powder preparation, as well as the drastic size difference between WC nanoparticles (APS $150 \mathrm{~nm}$ ) and Invar powder (325 mesh). The literature has demonstrated that extensive ball milling processing will promote the dispersion of nanoparticles in the interior of metal powder, which, in turn, gives rise to a uniform dispersion of nanoparticles in the matrix after sintering $[17,18]$. Without ball milling, the WC nanoparticles remained at the surface of Invar powder after mixing. During sintering and forging, the WC nanoparticles had very limited mobility and hence were unable to travel into the Invar grains. In this work, forging was shown to be effective in densification, removing the
Table 1 Mechanical properties of Invar-10WC comparing with a commercial Invar 36 alloy

\begin{tabular}{lllll}
\hline & $\begin{array}{l}\text { Young's } \\
\text { modulus } \\
(\mathrm{GPa})\end{array}$ & $\sigma_{\mathrm{y}}(\mathrm{MPa})$ & $\sigma_{\mathrm{UTS}}(\mathrm{MPa})$ & $\begin{array}{l}\text { Elon- } \\
\text { gation } \\
(\varepsilon)(\%)\end{array}$ \\
\hline Annealed & & & & \\
$\quad$ Invar-10WC & 180 & 440 & 795 & 22.7 \\
$\begin{array}{l}\text { Commercial Invar } \\
\quad 140\end{array}$ & 276 & 448 & 35 \\
$\quad 36$ [21] & & & & \\
$\begin{array}{l}\text { Cold-rolled } \\
\text { Invar-10WC }\end{array}$ & 185 & 950 & 1050 & 4.5 \\
$\quad$ Commercial Invar & 145 & 679 & 717 & 5.5 \\
$\quad 36$ [21] & & & & \\
\hline
\end{tabular}

sintering defects, and mechanically breaking apart large WC-rich clusters to smaller ones. A thermodynamic study in the literature has demonstrated that WC has around 2 at $\%$ solubility in $\mathrm{Fe}$ and $\mathrm{Ni}$ matrix at $1200^{\circ} \mathrm{C}$ and will react with molten $\mathrm{Ni}$ and Fe to form a $\mathrm{M}_{6} \mathrm{C}$-type alloy carbide [19]. For these reasons, upon experimentation of different sintering times and temperatures, sintering was carried out at $1300^{\circ} \mathrm{C}$ for a relatively short duration of $20 \mathrm{~min}$, in which no obvious growth or reaction of WC nanoparticles was observed.

\subsection{Mechanical behavior of Invar-10WC}

The mechanical properties of Invar-10WC in comparison with a commercial Invar 36 alloy are summarized in Table 1. The Young's modulus of the Invar-10WC sample is in close accordance with the volumetric rule of mixture when using $E_{\mathrm{WC}}=550 \mathrm{GPa}$ [20] and $E_{\text {Invar }}=140 \mathrm{GPa}$ [21]. The yield strength and tensile strength of the annealed Invar-10WC are increased by $60 \%$ and $77 \%$, respectively, compared with the commercial alloy, while for cold-rolled Invar-10WC, the values increased by $40 \%$ and $46 \%$, respectively. This strengthening effect is primarily due to the combined effect of Orowan strengthening, in which the nanoparticles impede the dislocation motion, and load transfer effect, in which the load is transferred from the matrix to the nanoparticle via strong interfacial bonding $[22,23]$. The salient strengthening is achieved at the expense of $35 \%$ of the material's ductility in annealed state and $18 \%$ in cold-rolled state.

\subsection{Thermal expansion behavior of Invar-10WC}

The CTE values of the Invar-10WC and the Invar-OWC, as a control, samples at selected temperatures are compared with a commercial Invar 36 alloy in Table 2 [21]. The Invar-OWC sample in this work exhibits slightly higher CTE value than that of the commercial alloy after the same heat 
Table 2 CTE of Invar-10WC, Invar-0WC, and a commercial Invar 36 alloy at selected temperature

\begin{tabular}{llll}
\hline $\begin{array}{l}\text { Temperature } \\
\left({ }^{\circ} \mathrm{C}\right)\end{array}$ & $\mathrm{CTE}, a\left(\times 10^{-6} /{ }^{\circ} \mathrm{C}\right)$ & \\
\cline { 2 - 4 } & Invar-10WC & Invar-0WC & $\begin{array}{l}\text { Commercial } \\
\text { Invar 36 [21] }\end{array}$ \\
\hline 100 & 2.61 & 1.65 & 1.50 \\
150 & 2.68 & 2.12 & 2.11 \\
260 & 3.39 & 4.48 & 4.18 \\
370 & 6.06 & 7.70 & 7.60 \\
\hline
\end{tabular}

treatment. This is likely the result of contamination and oxidation issues of powder metallurgical processing compared to the casting process in commercial production scale. The CTE value of the Invar-10WC sample is found to deviate slightly from the volumetric rule of mixture in the temperature range of $20-100^{\circ} \mathrm{C}$. This is likely due to the presence of some contaminants on the commercial WC nanoparticles as well as minor dissolution of WC into the Invar matrix [19] during sintering and forging, which was not directly observed in the SEM analysis. While the CTE of Invar-10WC is higher than that of unreinforced Invar-0WC from room temperature to $210^{\circ} \mathrm{C}$, a noticeable crossover between the two CTE versus temperature curves occurs around $210^{\circ} \mathrm{C}$, above which the CTE of the composite sample is lower than that of the unreinforced sample.

Due to its hexagonal crystal structure, $a$-WC has two distinctive linear CTE values on its a-axis $\left(a_{\mathrm{a}}\right)$ and c-axis $\left(a_{\mathrm{c}}\right)$. The $a_{\mathrm{a}^{\prime}} a_{\mathrm{c}^{\prime}}$ and mean linear CTE values of WC at elevated temperature are not reported in the literature. The volumetric $\mathrm{CTE}, a_{\mathrm{V}}$, of WC at elevated temperature was reported by Reeber et al. [24]. It was reported that the volumetric CTE versus temperature curve follows a logarithmic pattern, in which the CTE value grows fast from 0 to $230^{\circ} \mathrm{C}$ and slows down after $230^{\circ} \mathrm{C}$, eventually reaching a plateau above $800{ }^{\circ} \mathrm{C}$ [24]. To this end, the thermal expansion behaviors of Invar-10WC and Invar-0WC samples can be better understood. The CTE of the Invar-OWC sample follows that of commercial Invar 36, which show an increase in CTE when above its Curie temperature. The Invar-10WC sample only suffers a higher CTE value below $210{ }^{\circ} \mathrm{C}$, but benefits from the lack of Curie point and the slow growing CTE of WC above $230^{\circ} \mathrm{C}$, which results in the overall lower CTE value of the nanocomposite sample, when compared to that of regular Invar 36 alloy.

\section{Conclusions}

In this work, Invar reinforced by WC nanoparticles with high strength, low thermal expansion, and moderate ductility was manufactured using a simple powder metallurgy method. It was found that the Invar-10WC nanocomposite reached the highest tensile strength of $1050 \mathrm{MPa}, 4.5 \%$ ductility, together with a very low CTE value of $2.61 \times 10^{-6} /{ }^{\circ} \mathrm{C}$. This combination of UTS and CTE extends the low CTE alloy property space on the Ashbytype diagram, as displayed in Fig. 3, which is promising for significant applications. The Invar-10WC nanocomposite also had a lower CTE than that of regular Invar alloy above $210^{\circ} \mathrm{C}$, due to the incorporation of WC which has low CTE at elevated temperature, which could lead to potential high-temperature applications of Invar-WC nanocomposites.

Acknowledgments We acknowledge the financial support from the National Science Foundation.

\section{Compliance with ethical standards}

Conflict of interest The authors declare that they have no conflict of interest.

\section{References}

1. Martienssen W, Warlimont $\mathrm{H}$ (2005) Springer handbook of condensed matter and materials data. Springer, Berlin, $\mathrm{p} 783$

2. Salvo M, Casalegno V, Suess M, Gozzelino L, Wilhelmi C (2018) Laser surface nanostructuring for reliable Si3N4/Si3N4 and Si3N4/invar joined components. Ceram Int 44:12081-12087

3. Liu H, Sun Z, Wang G, Sun X, Li J, Xue F, Peng H, Zhang Y (2016) Effect of aging on microstructures and properties of Mo-alloyed Fe-36Ni invar alloy. Mater Sci Eng A 654:107-112

4. Chen C, Ma B, Miao S, Liu B (2018) Effect of cobalt on microstructure and mechanical properties of invar alloy. In: Han Y (ed) Advances in materials processing. CMC 2017. Lecture notes in mechanical engineering, vol 2017. Springer, Singapore, pp 855-864

5. Morikawa T, Moronaga T, Higashida K (2006) Fine-grained structures associated with deformation twin and its influence on tensile behaviours in a cold-rolled Fe-Ni alloy. Mater Sci Forum 503:895-900

6. Nakama K, Tatsutani S, Sugita K, Shirai Y (2014) Strengthening of $\mathrm{Fe}-36 \mathrm{mass} \% \mathrm{Ni}$ low thermal expansion alloy by additions of $\mathrm{C}$, $\mathrm{V}, \mathrm{Ti}$, and $\mathrm{Cr}$ and the effect of reducing $\mathrm{Ni}$ on thermal expansion. $J$ Jpn Inst Met Mater. 78(1):37-44 (in Japanese)

7. Nakama K, Furuya S, Sugita K, Inoue K, Shirai Y (2013) Lattice defects of cold-drawn and aged Fe-36 wt\%Ni alloys and effects of additions of $C$ and $V$ on hardness and thermal expansion. J Jpn Inst Met Mater 99(5):380-389 (in Japanese)

8. Vinogradov A, Hashimoto S, Kopylov VI (2003) Enhanced strength and fatigue life of ultra-fine grain $\mathrm{Fe} / 36 \mathrm{Ni}$ invar alloy. Mater Sci Eng A 355:277-285

9. Nakama K, Sugita K, Shirai Y (2013) Effect of MC type carbides on age hardness and thermal expansion of $\mathrm{Fe}-36 \mathrm{wt} \% \mathrm{Ni}-0.2 \mathrm{wt} \% \mathrm{C}$ alloy. Metallogr Microstruct Anal 2:383-387

10. Yahagi S, Kusaka K, Kato T (1980) Effect of Ni and Ti on the thermal expansion of Fe-Ni-Co-Ti alloys. Denki-Seiko 51(2):80-89 (in Japanese)

11. Sridharan K, Worzala FJ, Dodd RA (1992) Heat treatment and microstructure of an $\mathrm{Fe}-\mathrm{Ni}-\mathrm{Co}$ invar alloy strengthened by intermetallic precipitation. Mater Charact 29:321-327 
12. Liu Y, Liu L, Wu Z, Li J, Shen B, Hu W (2010) Grain growth and grain size effects on the thermal expansion properties of an electrodeposited Fe-Ni invar alloy. Scr Mater 63:359-362

13. Liu Y, Liu L, Shen B, Hu W (2011) A study of thermal stability in electrodeposited nanocrystalline Fe-Ni invar alloy. Mater Sci Eng A 528:5701-5705

14. Li X, Stampfl J, Prinz FB (2000) Mechanical and thermal expansion behavior of laser deposited metal matrix composites of Invar and TiC. Mater Sci Eng A 282:86-90

15. Kurlov AS, Gusev Al (2013) Tungsten carbides: structure, properties and application in hardmetals. Springer, Berlin

16. ASTM E228-17 (2017) Standard test method for linear thermal expansion of solid materials with a push-rod dilatometer. ASTM International, West Conshohocken

17. Karak SK, Dutta Majumdar J, Witczak Z, Lojkowski W, Manna I (2013) Microstructure and mechanical properties of nano- $\mathrm{Y}_{2} \mathrm{O}_{3}$ dispersed ferritic alloys synthesized by mechanical alloying and consolidated by hydrostatic extrusion. Mater Sci Eng A 580:231-241
18. Laurent-Brocq $M$, Legendre F, Mathon $M H$, Mascaro A, Poissonnet $S$, Radiguet B, Pareige $P$, Loyer M, Leseigneur O (2015) Influence of ball-milling and annealing conditions on nanocluster characteristics in oxide dispersion strengthened steels. Acta Mater 60:7150-7159

19. Fernandes CM, Senos AMR (2011) Cemented carbide phase diagrams: a review. Int J Refract Metal Hard Mater 29:405-418

20. Cardarelli F (2008) Materials handbook: a concise desktop reference. Springer, Berlin, p 640

21. CarTech Invar 36 Alloy Technical Datasheet, Carpenter Technology Corporation, Philadelphia, PA (2004)

22. Sanaty-Zadeh A (2012) Comparison between current models for the strength of particulate-reinforced metal matrix nanocomposites with emphasis on consideration of Hall-Petch effect. Mater Sci Eng A 531:112-118

23. Casati R, Vedani M (2014) Metal matrix composites reinforced by nano-particles - a review. Metals 4:65-83

24. Reeber RR, Wang K (1999) Thermophysical properties of alphatungsten carbide. J Am Ceram Soc 82(1):129-135 